\title{
Effects of Mo segregation on Charpy absorbed energy in Ti-12Mo alloys.
}

\author{
Satoshi Emura*, Xin Ji, Xiaohua Min ${ }^{* 2}$ and Koichi Tsuchiya \\ National Institute for Materials Science, Tsukuba, Japan \\ * Corresponding author: EMURA.Satoshi@nims.go.jp \\ *2 Dalian University of Technology, Dalian, P. R. China
}

\begin{abstract}
$\underline{\text { Abstract }}$
Beta phase stabilizing elements such as Mo have strong tendency to segregate. We have introduced swirly type segregation of Mo in Ti12Mo (mass \%) alloy through groove bar rolling. After solution treatment and low temperature aging, hard omega phase was precipitated heterogeneously, which improved the room temperature tensile elongation values without sacrificing tensile strength. In this study, the effect of Mo segregation and heterogeneous distribution of omega phase on Charpy absorbed energy was investigated in Ti12Mo alloy. Samples with two types of segregation were prepared; namely, swirly segregation in bar rolled sample and layered segregation in plate rolled sample. For comparison, we have also prepared Ti-12Mo bar samples with lesser Mo segregation, through high temperature thermomechanical treatment. Charpy impact tests were carried out at room temperature, $373 \mathrm{~K}$ and $473 \mathrm{~K}$, respectively, using the samples after aging to introduce isothermal omega-phase. The samples with the segregation exhibited higher Charpy absorbed energy, especially at higher temperature of $473 \mathrm{~K}$, while the sample with the swirly segregation showed higher Charpy absorbed energy than that with the layered segregation. The sample with lesser Mo segregation exhibited brittle intergranular fracture surface after Charpy testing. On the contrary, samples with Mo segregation exhibited ductile transgranular fracture surfaces.
\end{abstract}

\section{Introduction}

Beta-type Ti-Mo alloys are promising material for off-shore structure and bio-medical applications with their superior corrosion resistance [1]. However, Mo is prone to segregation, namely uneven distribution in Ti. To reduce this segregation, we need additional process [2], and also additional cost. We have been trying to control this segregation structure for property enhancement of Ti-Mo alloys, and have successfully introduced swirly segregation of Mo in Ti-12Mo (mass \%) alloy through groove bar rolling [3, 4]. After solution treatment and low temperature aging, hard second phase (omega phase) was precipitated heterogeneously, which improved the room temperature tensile elongation values without sacrifice of tensile strength [3, 4]. 
For the practical use of Ti-Mo alloys, strength-toughness balance is also very important as well as strength-ductility balance. In this study, we have investigated the effect of Mo segregation and heterogeneous distribution of omega phase on Charpy absorbed energy in Ti-12Mo alloy.

\section{Experimental}

We have prepared two types of Mo segregation, swirly segregation in bar rolled sample and layered segregation in plate rolled sample to check the effect of segregation structure on mechanical properties. The $70 \mathrm{~mm}$ diameter ingots of Ti-12Mo alloy prepared through cold crucible levitation melting (CCLM) were forged to $40 \mathrm{~mm}$ square slabs at $1273 \mathrm{~K}$. Some forged slabs were rolled to $14.3 \mathrm{~mm}$ square bars at $923 \mathrm{~K}$ for swirly segregation of Mo. Others were rolled to $12 \mathrm{~mm}$ thickness plate at $1073 \mathrm{~K}$ to obtain layered segregation of Mo. For comparison, we have also prepared Ti-12Mo bar samples with lesser Mo segregation. CCLM ingots were forged to $40 \mathrm{~mm}$ square slabs at higher temperature of $1473 \mathrm{~K}$, rolled to $17.5 \mathrm{~mm}$ square bars at $1473 \mathrm{~K}$, and then heat treated at $1473 \mathrm{~K}$ for $10.8 \mathrm{ks}$ to reduce the segregation. After the heat treatment, these bars were rolled at $923 \mathrm{~K}$ to $14.3 \mathrm{~mm}$ square bars. To precipitate omega phase, rolled samples were solution treated at $1073 \mathrm{~K}$ in beta single phase region and then aged at $523 \mathrm{~K}$ for $3.6 \mathrm{ks}$.

For observation of microstructure and segregation structure of Mo, scanning electron microscope (SEM) equipped with energy dispersed X-ray spectroscopy (EDS) was used.

Charpy impact tests were carried out at room temperature, $373 \mathrm{~K}$ and $473 \mathrm{~K}$, respectively, using $10 \times 10 \times 55 \mathrm{~mm}$ specimens with $2 \mathrm{~mm}$ notch. The longitudinal direction of specimens was consistent with the rolling direction. Fracture surfaces of Charpy tested specimens were observed by SEM.

\section{$\underline{\text { 3. Results and Discussion }}$}

Figure 1 shows the backscattered electron image (BEI) and elemental distribution maps of Mo obtained by EDS on RD planes (plane normal to the rolling direction) of Ti-12Mo samples after the heat treatment. All samples had similar equiaxed beta single phase microstructure with the grain size of around $100 \mathrm{~mm}$. In the BEI image, bright and dark contrasts of swirly or layered bands were clearly observed in samples processed at lower temperature (Fig. 1(a) and (b)). From EDS elemental map (Fig. 1(d) and (e)), the darker and brighter contrasts corresponded to Mo lean regions and Mo-rich regions, respectively. As for the bar rolled samples (Fig. 1(a) and (d)), the width of Mo segregation band seemed to be a little larger compared to that in our previous work [3, 4], because the finishing diameter of rolled bar was a little larger $(14.3 \mathrm{~mm}$ in this study and $11.8 \mathrm{~mm}$ in our previous work [3, 4]). On the contrary, bar rolled Ti12Mo samples processed at higher temperature exhibited less segregated microstructure (Fig. 1(c) and (f)). Hereafter, we call these three samples as swirly segregated sample, layered segregated sample and less segregated sample, respectively. 


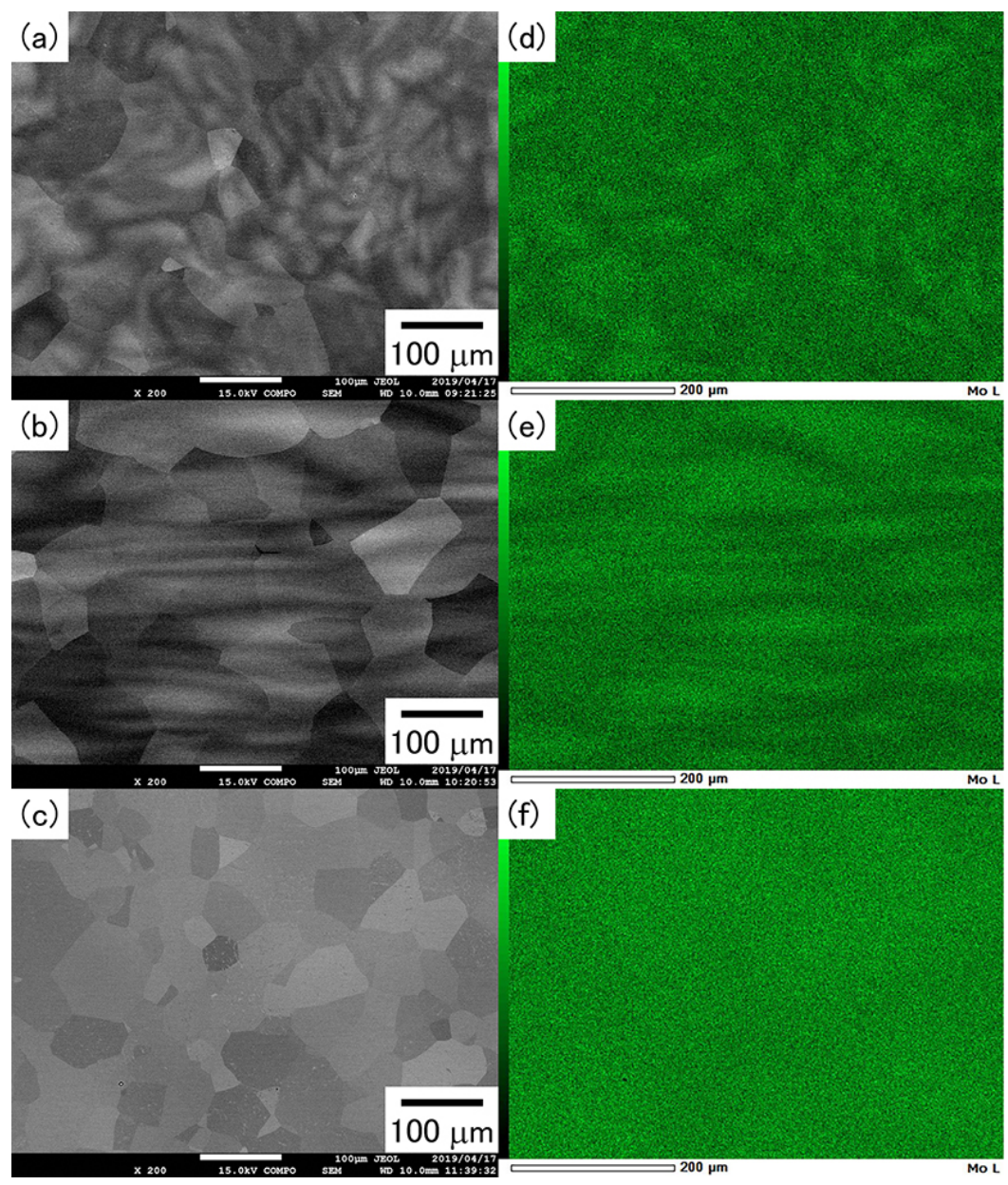

Fig. 1 Backscattered electron images ((a)-(c)) and elemental distribution maps of Mo ((d)-(f))

on RD planes of the samples after the heat treatment.

(a) and (d): swirly segregated sample, (b) and (e): layered segregated sample, (c) and (f): less segregated sample.

Figure 2 shows the BEI images on TD planes (plane parallel to the rolling direction) of Ti-12Mo samples after the heat treatment. On TD plane, Mo segregation bands aligned along the rolling direction in both swirly and layered segregated samples. From the EDS point analysis on these planes, variation in Mo content was more than $3 \%$ in both swirly and layered segregated samples, and around $1 \%$ in less segregated sample, respectively. 


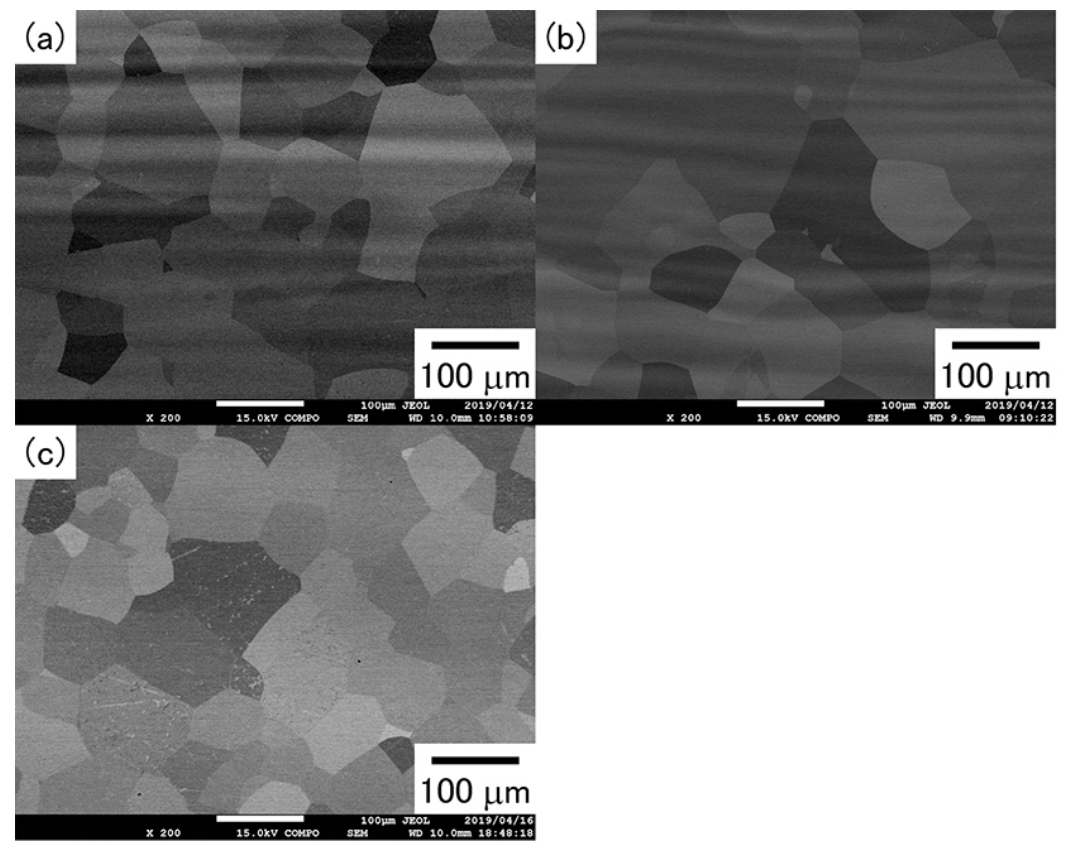

Fig. 2 Backscattered electron images in TD planes of the samples after the heat treatment.

(a): swirly segregated sample, (b): layered segregated sample, (c): less segregated sample.

The effect of Mo segregation (heterogeneous distribution of omega phase) on Charpy absorbed energy in Ti-12Mo alloy was shown in Fig. 3. At room temperature, difference of Charpy absorbed energy was not so significant. As testing temperature increased, samples with segregation exhibited higher Charpy absorbed energy, especially at higher temperature of $473 \mathrm{~K}$. Swirly segregated sample showed higher Charpy absorbed energy than that of layered segregated sample. 


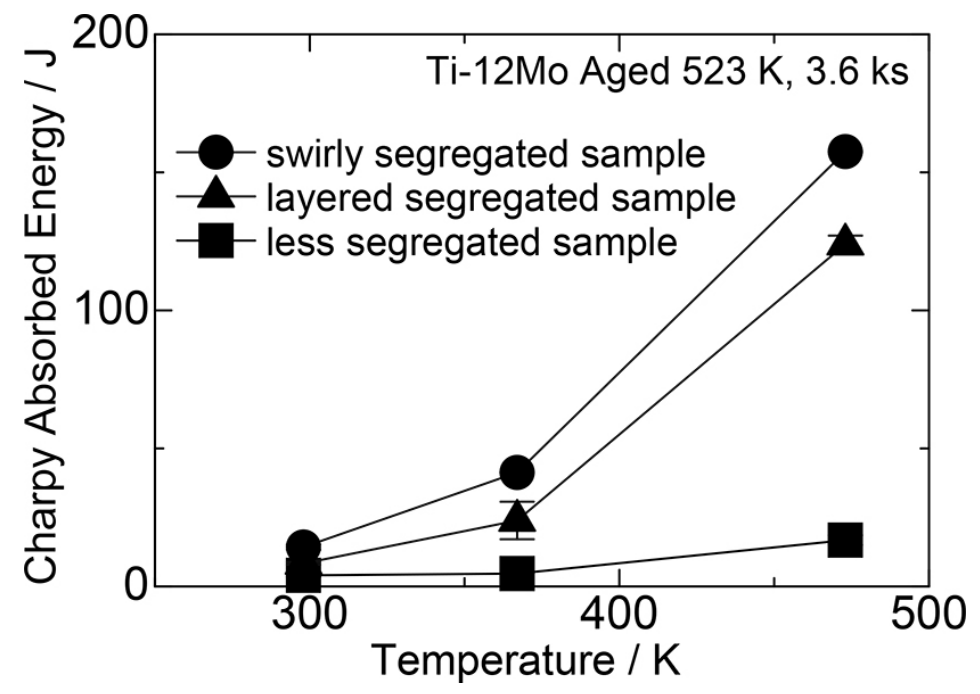

Fig. 3 Effect of Mo segregation on Charpy absorbed energy in Ti-12Mo alloy.

Figure 4 exhibits the fracture surfaces of Charpy tested specimens at room temperature. Although there was no significant difference in the Charpy absorbed energy at room temperature, the fracture surface of less segregated sample exhibited the brittle intergranular fracture features, which was different from the somewhat ductile transgranular fracture features in both swirly and layered segregated samples. Figure 5 shows the fracture surfaces of Charpy tested specimens at $473 \mathrm{~K}$. The fracture surface of less segregated sample still had brittle intergranular fracture features. On the contrary, both swirly and layered samples exhibited ductile dimple fracture features. So far the reason for this difference of fracture features was not clear, but heterogeneous distribution of hard omega phase seems to cause the ductile fracture. 

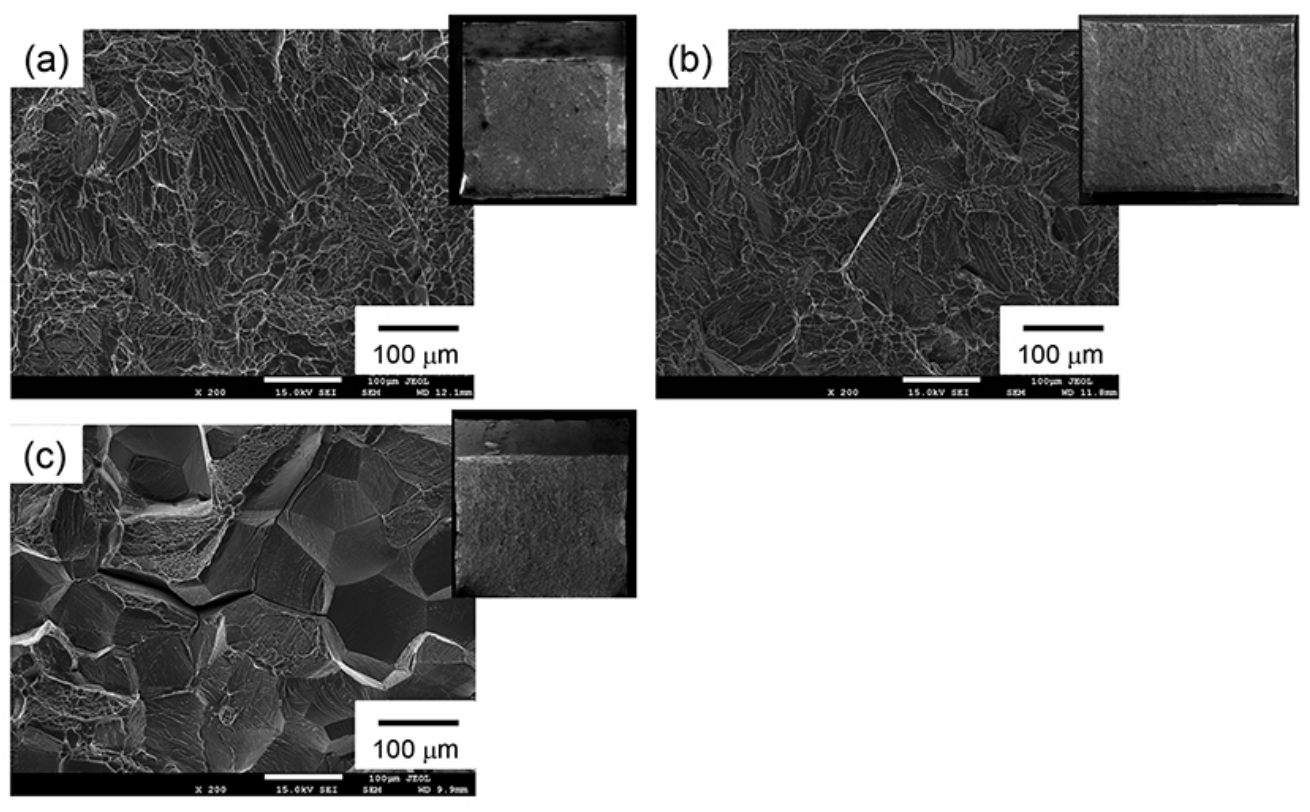

Fig. 4 Fracture surfaces of Charpy tested specimens at room temperature.

(a): swirly segregated sample, (b): layered segregated sample, (c): less segregated sample. 

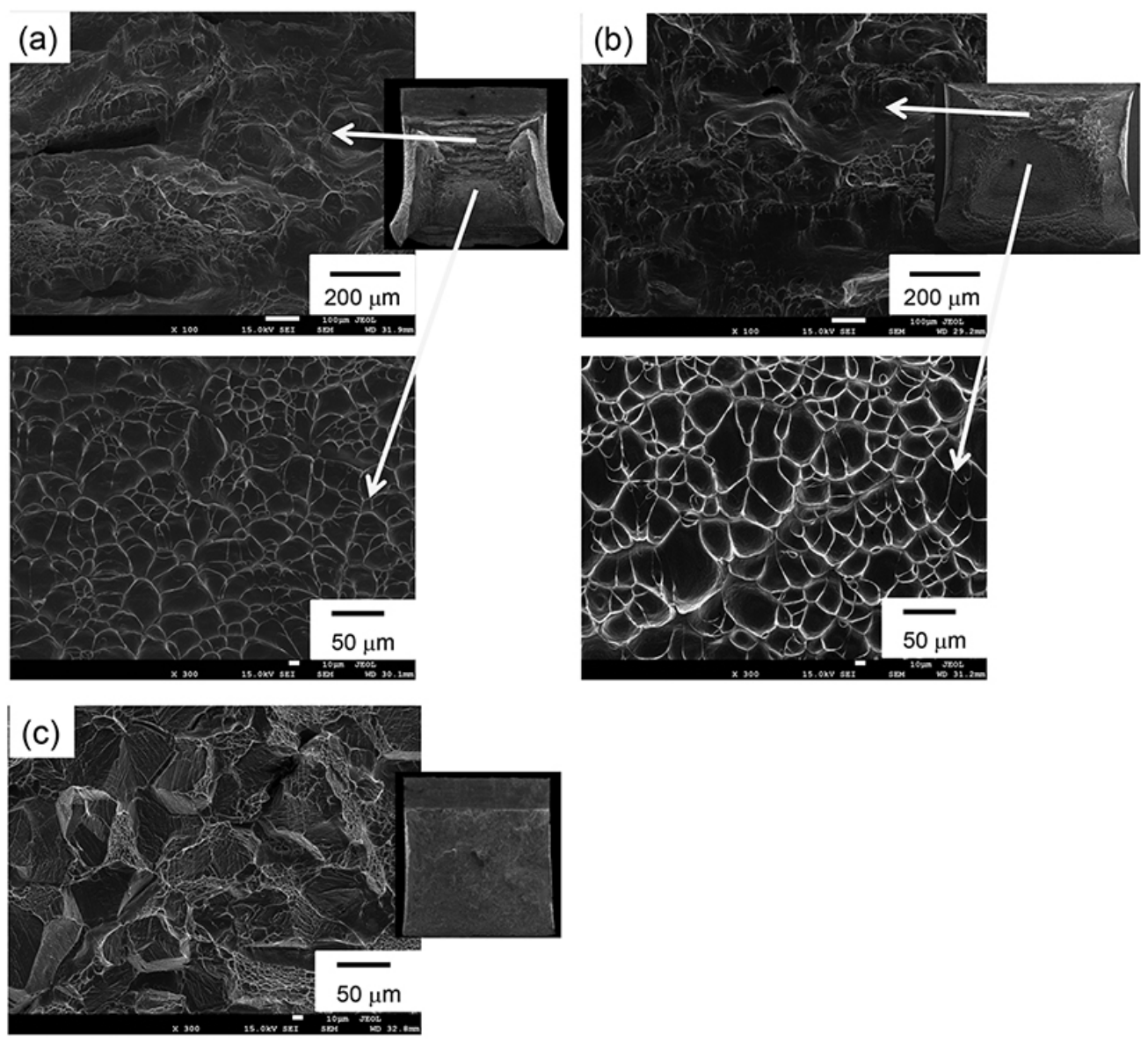

Fig. 5 Fracture surfaces of Charpy tested specimens at $473 \mathrm{~K}$.

(a): swirly segregated sample, (b): layered segregated sample, (c): less segregated sample.

\section{Conclusion}

In this study, we have investigated the effect of Mo segregation and heterogeneous distribution of omega phase on Charpy absorbed energy in Ti-12Mo alloy. Samples with segregation exhibited higher Charpy absorbed energy, especially at higher temperature of 473 K. Sample with swirly segregation showed higher Charpy absorbed energy than that with layered segregation. Sample with lesser Mo segregation exhibited brittle intergranular fracture surface after Charpy testing. On the contrary, samples with Mo segregation exhibited ductile transgranular fracture surfaces. 


\section{$\underline{\text { 5. Acknowledgement }}$}

This work was partly supported by JSPS KAKENHI Grant Number JP26420733.

\section{References}

[1] T. Nishimura, J. Power Energy Syst., Vol. 2 (2008), 530-537.

[2] T. Zhou, G. Itoh, Y. Motohashi and M. Niinomi, Mater. Trans., Vol. 47 (2006), 90-95.

[3] S. Emura, X. H. Min, S. Ii, K. Tsuzaki and K. Tsuchiya, Proc. 12th World Conference on Titanium (Ti-2011), Science Press, Beijing, 2012, pp. 536-539.

[4] S. Emura, X. H. Min, S. Ii and K. Tsuchiya, Key Engineering Materials, 551(2013), 180-185. 